\title{
POLY(4-VINYLBENZYL)TRIMETHYLAMMONIUM CHLORIDE) RESIN WITH REMOVAL PROPERTIES FOR VANADIUM(V) AND MOLYBDENUM(VI). A THERMODYNAMIC AND KINETIC STUDY
}

\author{
DANIELA V. MORALES ${ }^{1}$, BERNABÉ L. RIVAS ${ }^{2 *}$ AND MARIANELA GONZÁLEZ ${ }^{2}$ \\ ${ }^{1}$ Department of Environmental Chemistry, Faculty of Sciences, Universidad Católica de la Santísima Concepción, Concepción, Chile. \\ ${ }^{2}$ Department of Polymers, Faculty of Chemistry, University of Concepción, Casilla 160-C, Concepción, Chile.
}

\begin{abstract}
Ion exchange resin poly(4-vinylbenzyl) trimethylammonium chloride(P(ClVBTA)) was synthesized and its removal properties toward vanadium(V) and molybdenum(VI) were evaluated and compared with those of the Amberlite IRA-402 commercial resin. The resin was characterized by FT-IR spectroscopy, TGA, and SEM. The water absorption capacity, $\mathrm{pH}$ effect, Langmuir and Freundlich adsorption isotherms, and kinetic model parameters were determined. All studies were conducted through a batch equilibrium procedure. Thermodynamic parameters, including enthalpy, entropy, and free energy, were determined. The P(ClVBTA) resin showed faster and higher capacity for the removal of $\mathrm{V}(\mathrm{V})$ and $\mathrm{Mo}(\mathrm{VI})$ from a water solution than the Amberlite IRA-402 commercial resin with the same ammonium salt functional group. The higher capacity of the P(ClVBTA) resin was attributed to the higher degree of swelling, the exfoliation in the monolayer, and the small particle size.
\end{abstract}

Keywords: Resins, removal, molybdenum, vanadium.

\section{INTRODUCTION}

With the fast development of metal plating facilities, mining operations, fertilizer industries, tanneries, batteries, paper industries, and pesticides, among other industries, heavy metal wastewaters are increasingly directly or indirectly discharged into the environment, especially in developing countries. In contrast to organic contaminants, heavy metals are not biodegradable and tend to accumulate in living organisms, and many heavy metal ions are known to be toxic or carcinogenic. ${ }^{1}$

Heavy metal pollution has become one of the most severe environmental problems. The treatment of heavy metals is of special concern due to their recalcitrance and persistence in the environment. In recent years, various methods for heavy metal removal from wastewater have been extensively studied. ${ }^{2-9}$ These procedures and technologies include chemical precipitation, ion-exchange, adsorption, membrane filtration, coagulation-flocculation, flotation, and electrochemical methods. According to the literature survey articles, ion-exchange, adsorption and membrane filtration methods are the most frequently studied for the treatment of heavy metal wastewater. ${ }^{10-17}$

Among the metal ions, as oxyanions, molybdenum and vanadium occur in the earth crust in mean concentrations of approximately $0.0001 \%$ and $150 \mathrm{~g} \mathrm{t}^{-1}$, respectively.

Therefore, vanadium is one of the most commonly found metals. Since the 1980s, a new type of secondary raw materials has gained importance for the production of these metals, namely, the molybdenum-containing catalysts, which are widely used in the petroleum refining industry. As environmental legislation is becoming strict, the emission and deposition of these residues must be drastically reduced.

Equilibrium in aqueous solutions of molybdenum(VI) has been studied in detail. At molybdenum concentrations exceeding $10^{-3} \mathrm{~mol} \mathrm{l}^{-1}$ at $\mathrm{pH}>6$, the predominant species is the tetrahedral $\left[\mathrm{MoO}_{4}\right]^{2-}$ ion. As the $\mathrm{pH}$ is lowered, polymerization condensation occurs, which yields at $\mathrm{pH} 5-6$ the heptamolybdate ion $\left[\mathrm{Mo}_{7} \mathrm{O}_{24}\right]^{6-}$ and at $\mathrm{pH}$ 3-5 the octamolybdate ion $\left[\mathrm{Mo}_{8} \mathrm{O}_{26}\right]^{4-}$. Both ions are constructed from linked octahedral $\mathrm{MoO}_{6}$. At $\mathrm{pH} 0.9, \mathrm{MoO}_{3}$ precipitates, and in more acidic solutions, the $\left[\mathrm{MoO}_{2}\right]^{2+}$ ion is formed.

The typical source of molybdenum in physiological studies is a molybdate, but it is not always clearly stated in the literature precisely which compound has been used. For example,"ammoniummolybdate" may refer to $\left(\mathrm{NH}_{4}\right)_{2} \mathrm{MoO}_{4}$, $\left(\mathrm{NH}_{4}\right)_{2} \mathrm{Mo}_{2} \mathrm{O}_{7}$ (dimolybdate), or $\left(\mathrm{NH}_{4}\right)_{6} \mathrm{Mo}_{7} \mathrm{O}_{24} \cdot 4 \mathrm{H}_{2} \mathrm{O}$ (heptamolybdate). Due to the chemical similarities of the various molybdate species and since they are in equilibrium in aqueous media,substantial differences are unlikely in terms of their physiological effects. ${ }^{18-20}$ However, compared with tungsten, Mo sorption is more $\mathrm{pH}$-sensitive. In strongly acidic solutions, molybdate(VI) oxoanions can convert to molybdenylcations, namely, $\mathrm{MoO}^{22+} \cdot{ }^{21}$ At higher $\mathrm{pH}$, molybdenum polyanions are converted into simple molybdates, namely, $\mathrm{MoO}_{4}{ }^{2-}$. This can strongly impact molybdenum adsorption onto polyol adsorbents.

Vanadium occurs in living organisms in very small amounts. The total amount of vanadium in the human body is estimated to be less than 1 milligram (0.000035 ounce). It is found most commonly in the kidneys, spleen, lungs, testes, and bones. No function for vanadium in humans has been identified. In large doses, vanadium can be toxic to humans and other animals. Excessive vanadium compounds have been demonstrated to be toxic and possibly carcinogenic, while an overdose of molybdenum may induce copper deficiency, ${ }^{22}$ thereby causing problems with the transfer of oxygen from blood to other cells.

The chemistry of vanadium is even more complicated than that of molybdenum. Similar to molybdenum, vanadate $(\mathrm{V})$ can be converted into a form of vanadyl(V) cation, namely, $\mathrm{VO}^{2+}$. Yellow vanadate $(\mathrm{V})$ oxoanions can also be reduced to blue vanadyl(IV) cations, namely, $\mathrm{VO}^{2+} \cdot{ }^{23}$ Changes in the adsorptivity of these species can play an important role in their mutual separations.

The objective of this paper is to evaluate the removal properties of poly(4vinylbenzyl) trimethylammonium chloride(P(ClVBTA)), which is a waterinsoluble polymer thatcontains a quaternary ammonium group for molybdenum and vanadium under various experimental conditions.P(CIVBTA) resin was studied by the research group for the recovery of chromium, arsenite, and arsenate from water. ${ }^{24-26}$

\section{EXPERIMENTAL}

\section{Materials}

The reagents used to synthesize the ion-exchange resins and the poly(4vinylbenzyl) trimethylammonium chloride( $\mathrm{P}(\mathrm{ClVBTA})$ ) resin were the monomer (4-vinylbenzyl) trimethylammonium chloride $(99 \%)$ and $\mathrm{N}, \mathrm{N}^{\prime}$ methylene-bis-acrylamide (99\%) and ammonium persulfate $(98 \%)$ as the crosslinking reagent and the initiator, respectively. All these reagents and the AmberliteIRA-402 commercial resin were purchased from Sigma-Aldrich. The reagents used to investigate the removal properties were ammonium metavanadate(p.a.), ammonium heptamolybdate $(99 \%)$, hydrochloric acid $(37 \%)$, and nitric acid (65\%). All the salts and acid solutions were purchased from Merck. 


\section{Synthesis of the $\mathrm{P}(\mathrm{CIVBTA})$ resin}

The $\mathrm{P}(\mathrm{ClVBTA})$ resin was synthesized at laboratory scale by radical polymerization using a (4-vinylbenzyl) trimethylammoniumchloride, $\mathrm{N}, \mathrm{N}^{\prime}$ methylene-bis-acrylamide ( $4 \mathrm{~mol} \%$ ), and $1 \mathrm{~mol} \%$ of ammonium persulfate as the monomer, crosslinking reagent, and initiator, respectively. All the reagents were introduced into a polymerization flask with $10 \mathrm{~mL}$ of water and were placed under a $\mathrm{N}_{2}$ atmosphere for $24 \mathrm{~h}$ at $70^{\circ} \mathrm{C}^{24}$ The resin was filtered, washed with distilled water, and dried in an oven at $40^{\circ} \mathrm{C}$ until a constant weight was obtained. Finally, the dry resin was milled and sieved to obtain particles with sizes that were between 250 and $180 \mu \mathrm{m}$.

The synthetic route of the $\mathrm{P}(\mathrm{ClVBTA})$ resin is illustrated in Figure 1. The structure of the Amberlite IRA-402 commercial resin, which was used as reference is shown in Figure 2.
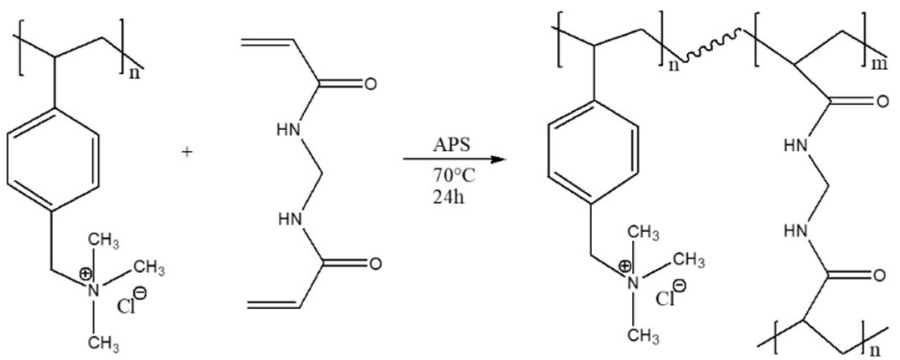

Figure 1. Synthetic route of $\mathrm{P}(\mathrm{ClVBTA})$ resin.

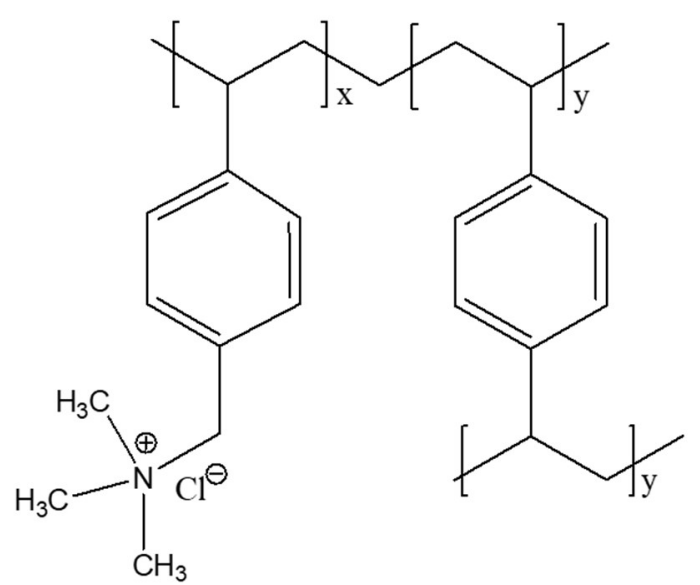

Figure 2. Structure of Amberlite IRA-402 commercial resin.

\section{Instrumentation}

The laboratory equipment that was used in the experimental stage of this research included the following: (a) a Shimadzu AUX 220 analytical balance; (b) a Wisebath thermostatic bath; (c) a Memmert heater; (d) a Perkin Elmer PinAAcle 900F atomic absorption spectrometer; (e) a Toledo seven compact digital pH meter; (f) a Wisestir MSH-20a magnetic stirrer; (g) a Jeol JSM-6380 LV scanning electron microscope; (h) a Magna Nicolet TF-IR spectrometer 550; (i) a Netzsch 209F1 Iris 2020-1 thermogravimetric analyzer; (j) a set of stainless steel sieves of sizes 100, 180, and $250 \mu \mathrm{m}$; (k) an IKA A11 basic grinder; (1) a Spectra/Chrom CF-2 fraction collector; and (m) a Kross Flo research I peristaltic pump.

\section{Characterization}

The $\mathrm{P}(\mathrm{ClVBTA})$ resin was characterized by FT-IR spectroscopy over the range of 400 to $4000 \mathrm{~cm}^{-1}$ to identify the typical absorption bands of the ion exchange resin and also by SEM (scanning electron microscopy) to observe the morphology of the resin at $100-1 \mu \mathrm{m}$. Finally, it was also analyzed by TGA (thermogravimetric analysis), and the profile of decomposition of the resin was identified between $0-550^{\circ} \mathrm{C}$ under $\mathrm{N}_{2}$ atmosphere and a heating rate of $10^{\circ} \mathrm{C} / \mathrm{min}$

\section{Degree of swelling}

The resin swelling analysis was conducted using $100 \mathrm{mg}$ of dry resin and 80 $\mathrm{mL}$ of bidistilled water, which were introduced into and stored in a $100-\mathrm{mL}$ beaker for $24 \mathrm{~h}$.For this study, the particle size was between 180 and $250 \mu \mathrm{m}$.

Once the residence time was completed, the beaker content was filtered, and the wet resin was weighed to obtain the mass of water that was absorbed per gram of resin (see Eq. 1). The resins were classified as (a) xerogel $\left(0 \mathrm{~g} \mathrm{H}_{2} \mathrm{O} \mathrm{g}\right.$ ${ }^{1}$ resin), (b) hydrogel (0-100 $\mathrm{g} \mathrm{H}_{2} \mathrm{O} \mathrm{g}^{-1}$ resin), and (c) superabsorbent (higher than $100 \mathrm{~g} \mathrm{H}_{2} \mathrm{O} \mathrm{g}^{-1}$ resin).

$$
\text { Degree of Swelling }=\frac{\text { Wet mass of resin }}{\text { Dry mass of resin }}
$$

\section{Batch procedure}

\section{Effect of the pH on the removal}

To study the $\mathrm{pH}$ effect on the metal ion removal, solutions of Mo(VI) and $\mathrm{V}(\mathrm{V})$ at $\mathrm{pH}$ values of $2,4,6,8,10$, and 12 were prepared. The $\mathrm{pH}$ values were adjusted with $\mathrm{HNO}_{3}$ and $\mathrm{NaOH}$. The resin $(0.05 \mathrm{~g})$ was contacted with a solution of 50 ppm of metal ion in a water bath at a constant agitation of $140 \mathrm{rpm}$ for $60 \mathrm{~min}$ and $25^{\circ} \mathrm{C}$. Afterward, the solutions were filtered and washed prior to analysis by atomic absorption spectroscopy (AAS). Thus, the optimal $\mathrm{pH}$ was determined, which corresponds to the $\mathrm{pH}$ at which the resin retained the largest amount of the metal ion.

\section{Thermodynamic parameter study}

To obtain the thermodynamic parameters for the $\mathrm{P}(\mathrm{ClVBTA})$ resin, an adsorption isotherm study was conducted by varying the concentration of metal ion at constant mass of the resin. The experiment was conducted after preparing 25-2200 ppmofthe metal ion solution and the resin mass $(50 \mathrm{mg})$, and the temperature was maintained constant with stirring at 140rpm for $24 \mathrm{~h}$. Then, the solutions were filtered and washed, and they were used for analysis by AAS. The adsorption isotherms were identified at 25,35 , and $45^{\circ} \mathrm{C}$.

The obtained data were adjusted according to the Langmuir and Freundlich isotherms, and whether the adsorption of the metal ion in the resin corresponds to a physical or chemical adsorption was determined. Equation (2) and equation (3) express the Langmuir and Freundlich linearized isotherms, respectively.

Langmuir Equation:

$\frac{C_{e}}{q_{e}}=\frac{1}{b q_{m}}+\frac{C_{e}}{q_{m}}$

$\mathrm{C}_{\text {eq }}$ : Equilibrium concentration $\left(\mathrm{mg} \mathrm{L}^{-1}\right)$

$\mathrm{q}_{\mathrm{e}}$ : Amount of metal ion that is adsorbed per unit weight of the resin (mg metal ion $\mathrm{g}^{-1}$ resin)

$\mathrm{q}_{\mathrm{m}}$ : Maximum adsorption capacity $\left(\mathrm{mg} \mathrm{g}^{-1} \mathrm{resin}\right)$

b: Langmuir constant $\left(\mathrm{L} \mathrm{mg}^{-1}\right)$

Freundlich equation: $\log \left(q_{-} e\right)=\log k_{-} F+1 / n \log C_{-}(e)$

$\mathrm{q}_{\mathrm{e}}$ : Amount of metal ion that is adsorbed per unit weight of the resin (mg metal ion $\mathrm{g}^{-1}$ resin)

$\mathrm{C}_{\mathrm{eq}}$ : Equilibrium concentration $\left(\mathrm{mg} \mathrm{L}^{-1}\right)$

$\mathrm{K}_{\mathrm{F}}$ : Freundlich constant

$\mathrm{n}$ : Dimensionless parameter that corresponds to the preference of the adsorption

\section{Kinetic Models}

To predict the mechanism of the adsorption process, two kinetic models were used: Lagergren pseudo-first-order and pseudo-second-order models. As usual, the sorption kinetics were described by pseudo-first-order or pseudo-secondorder models. ${ }^{27}$

The sorption kinetics follow the following pseudo-first-order equation:

$\frac{d q}{d t}=k_{1}\left(q_{e}-q_{t}\right)$ 
Table 1. Main FT-IR absorption bands of $\mathrm{P}(\mathrm{ClVBTA})$ and IRA-402(Cl)resins

\begin{tabular}{|c|c|c|c|c|}
\hline Resin & $-\mathbf{N H} / \mathbf{c m}^{-1}$ & $-\mathbf{N}^{+}-\left(\mathbf{C H}_{3}\right)_{3} / \mathbf{c m}^{-1}$ & $-\mathbf{C H}$ aromatic $/ \mathbf{c m}^{-1}$ & $-\mathbf{C}=\mathbf{O} / \mathbf{c m}^{-1}$ \\
\hline P(ClVBTA) & 3438.51 & 1483.02 & 3023.88 & 1643.08 \\
\hline IRA-402(Cl) & 3415.37 & 1481.09 & 3027.74 & 1646.94 \\
\hline
\end{tabular}

$q_{t}$ : Amount of adsorbed species $\left(\mathrm{mg} \mathrm{g}^{-1}\right)$ at time $\mathrm{t}$.

$q_{e}$ : Amount of adsorbed species $\left(\mathrm{mg} \mathrm{g}^{-1}\right)$ at the equilibrium time.

$k_{1}$ : Adsorption rate constant $\left(\mathrm{min}^{-1}\right)$.

Eq. (4) is integrated with respect to the following boundary conditions:

$q=0$ at $t=0,$, and $q=q_{t}$ att $=t$

This yields,

$\log \left(q_{e}-q_{t}\right)=\log \left(q_{e}\right)-\frac{k_{1}}{2.303}$

The adsorption rate constant $k_{1}\left(\mathrm{~min}^{-1}\right)$ can be calculated from the plot of $\log \left(q_{e}-q_{t}\right)$ versus time.

The kinetic data can be analyzed by means of pseudo-second-order kinetics:

$\frac{d q}{d t}=k_{2}\left(q_{e}-q_{t}\right)^{2}$

$\mathrm{k}_{2}$ : Pseudo-second-order rate constant $\left(\mathrm{g} \mathrm{mg}^{-1} \mathrm{~min}\right)$

$q_{t}$ : Amount of adsorbed species $\left(\mathrm{mg} \mathrm{g}^{-1}\right)$ at time t.

$q_{e}$ : Amount of adsorbed species $\left(\mathrm{mg} \mathrm{g}^{-1}\right)$ at the equilibrium time. Varying the variables in Eq. (6) yields

$\frac{d q}{\left(q_{e}-q_{t}\right)^{2}}=k_{2} d t$

And by integrating Eq. (7) for the following boundary conditions:

$t=0$ to $t=t$, and $q=0$ and $q=q_{e}$,

The final form is obtained:

$\frac{t}{q_{t}}=\frac{1}{k_{2} q_{e}^{2}}+\frac{1}{q_{e}} t$

A plot of $t / q$ versus $t$ gives yields the value of constant $k_{2}\left(\mathrm{~g} \mathrm{mg}^{-1} \mathrm{~min}\right)$. It is possible to calculate $q_{e}\left(\mathrm{mg} \mathrm{g}^{-1}\right)$.

\section{RESULTS AND DISCUSSION}

\section{Characterization by FT-IR spectroscopy}

Figure 3 presents the FT-IR spectra of P(ClVBTA) resin (circles) and IRA$402(\mathrm{Cl})$ resin (squares). In Table 1, the principal absorption bands for both are presented.

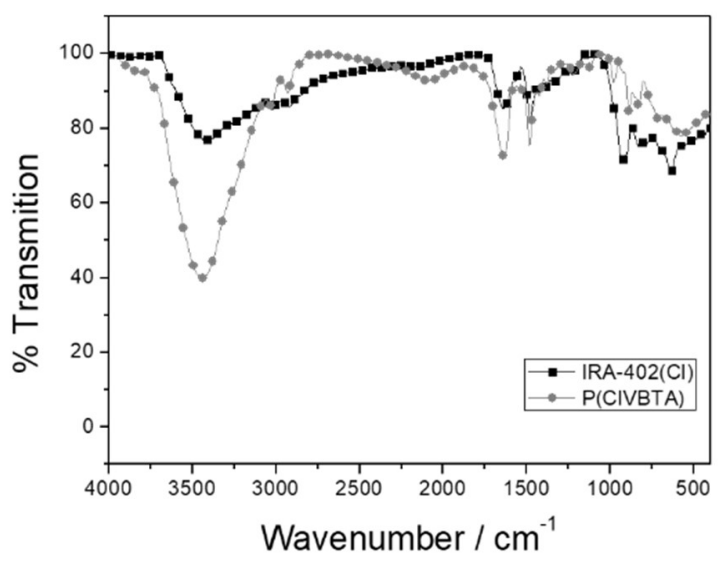

Figure 3. FT-IR spectra of $\mathrm{P}(\mathrm{ClVBTA})$ (circles) and IRA-402(Cl) (squares) resins.

\section{Scanning electron microscopy (SEM)}

The shape of the particles, the rugosity of the surface, and the porosity were investigated by SEM. It is important to examine the surface characteristics of a material that will be used in the adsorption process. A resin with a rough surface will have a larger available surface for interaction with an adsorbate.

An SEM analysis of $\mathrm{P}(\mathrm{CIVBTA})$ resin was conducted with particles of size $180-250 \mu \mathrm{m}$. For the P(ClVBTA) resin, in Figure 4.a), homogenous small particles were observed, which were irregularly shaped and non-uniform, and in Figures 4.b) and 4.c), a lack of rugosity and a small exfoliation were observed. For the commercial IRA-402(Cl) resin, in Figure 4.d) we observe particles of spherical and uniform shape, and in Figures 4.e) and 4.f) we observe exfoliation and porosity.
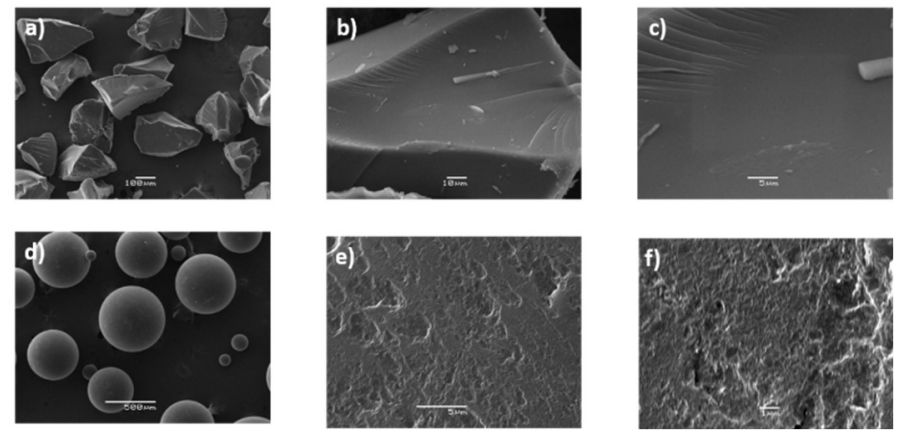

Figure 4. Microphotographs of $\mathrm{P}(\mathrm{ClVBTA})$ resin at magnifications of a) 100 $\mu \mathrm{m}$, b) $10 \mu \mathrm{m}$ and c) $5 \mu \mathrm{m}$ and of IRA-402(Cl) resin at magnifications of d) 500 $\mu \mathrm{m}$, e) $5 \mu \mathrm{m}$ and f) $1 \mu \mathrm{m}$.

\section{Thermogravimetric analysis (TGA)}

To obtain the decomposition profile of the P(ClVBTA) resin, the sample was subjected to controlled heating. Figure 5 presents a thermogram of the $\mathrm{P}(\mathrm{ClVBTA})$ resin, which was obtained under a nitrogen inert atmosphere at a heating rate of $10^{\circ} \mathrm{C} / \mathrm{min}$.

There is no significant decomposition temperature, and according to the thermogram, the $\mathrm{P}(\mathrm{ClVBTA})$ resin is stable up to approximately $250^{\circ} \mathrm{C}$. The $\mathrm{P}(\mathrm{ClVBTA})$ resin does not show a substantial loss of weight, which is likely due to adsorbed water molecules. Subsequently, it lost weight in two steps, which is likely due to the ammonium group weight loss.

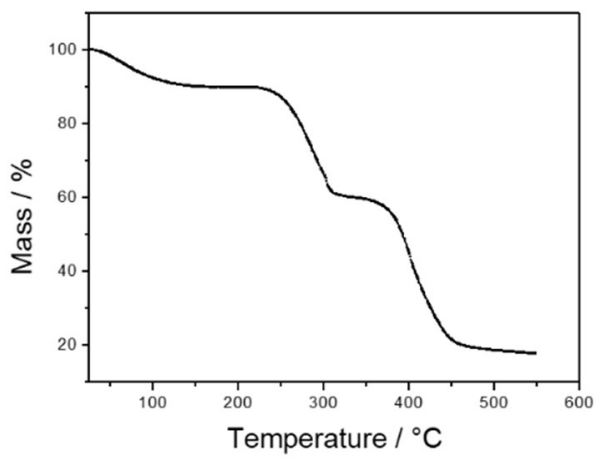

Figure 5.Thermogram of $\mathrm{P}(\mathrm{ClVBTA})$ resin.

\section{Degree of swelling}

The degree of swelling represents the capacity for water absorption, which is directly correlated with the number of available active sites for the removal of metal ions. The degree of swelling is the most important property that,theoretically, enables the metal ions to diffuse through the porous crosslinked matrix and favors the exchange of metal ions with functional groups.

The degree of swelling can be influenced by various characteristics of the polymer matrix structure, such as the crosslinking degree, concentration, $\mathrm{pK}$ of ionizable groups, ionization degree, and hydrophilicity, among others. 
According to the degree of swelling, it is possible to classify the resins as xerogelresins ( $0 \mathrm{~g} \mathrm{H}_{2} \mathrm{O} \mathrm{g}^{-1}$ resin), which areincapable of retaining water, or hydrogel resins (0 to $100 \mathrm{~g} \mathrm{H}_{2} \mathrm{O} \mathrm{g}^{-1}$ resin), which can retain water. In addition, superabsorbents ( $100 \mathrm{~g} \mathrm{H}_{2} \mathrm{O} \mathrm{g}^{-1}$ resin) are resins that absorb more water, thereby inhibiting ion exchange.

According to Table 2, the $\mathrm{P}(\mathrm{ClVBTA})$ resin and the IRA-402(Cl) commercial resin are both classified as hydrogels, but the $\mathrm{P}(\mathrm{ClVBTA})$ resin has a higher water absorption capacity than that commercial resin IRA-402(Cl), as it has more available active sites for metal ion removal.

Table 2. Degree of swelling for the $\mathrm{P}(\mathrm{ClVBTA})$ and IRA-402(Cl) resins.

\begin{tabular}{|c|c|}
\hline Resin & Water absorption $/ \mathbf{g ~ H}_{\mathbf{2}} \mathbf{O ~ g ~}^{-1}$ resin \\
\hline P(CIVBTA $)$ & 82.7 \\
\hline IRA-402(Cl) & 0.69 \\
\hline
\end{tabular}

\section{Effect of the pH on the adsorption}

With the objective of determining the effect of the $\mathrm{pH}$ on the adsorption, solutions of $\mathrm{Mo}(\mathrm{VI})$ and $\mathrm{V}(\mathrm{V})$ at $\mathrm{pH}$ values of 2, 4, 6, 8, 10, and 12and a concentration of $50 \mathrm{mg} \mathrm{L}^{-1}$ were prepared.

The speciation of molybdenum and vanadium differ according to the $\mathrm{pH}$ value, which will affect the structure. Table 3presents the speciation at various $\mathrm{pH}$ values.

According to Table 3, molybdenum at a $\mathrm{pH}$ lower than or equal to 1 , the ion has a positive charge, which leads an impossible ion exchange with ammonium quaternary functional groups, whereas at a $\mathrm{pH}$ that exceeds 2 , the removal will be possible due to the negative charge of the ion as an oxyanion species, which is favored by the resin structure.

Vanadium at a $\mathrm{pH}$ of less than 2 is positively charged; hence, removal by the $\mathrm{P}(\mathrm{ClVBTA})$ resin is impossible due to the ammonium quaternary functional groups. However, at values that exceed 2, vanadium is an oxyanion that favors the ion exchange due to its negative charge.

Table 3. Speciation of molybdenum and vanadium at various $\mathrm{pH}$ values.

\begin{tabular}{|c|c|c|c|}
\hline \multicolumn{2}{|c|}{ Molybdenum } & Vanadium & \\
\hline $\mathbf{p H}$ & species & $\mathbf{p H}$ & Species \\
\hline$>6.5$ & $\mathrm{MoO}_{4}{ }^{2-}$ & $>13$ & $\mathrm{VO}_{4}{ }^{3-}$ \\
\hline 4 & $\mathrm{MoO}_{24}{ }^{6-}$ & 9 & $\mathrm{~V}_{2} \mathrm{O}_{7}{ }^{4-}$ \\
\hline 2 & $\mathrm{Mo}_{8} \mathrm{O}_{26}{ }^{4-}$ & 8.5 & $\mathrm{VO}_{3}{ }^{-}$ \\
\hline$\leq 1$ & $\mathrm{MoO}_{2}{ }^{2+}$ & 6 & $\mathrm{~V}_{3} \mathrm{O}_{9}{ }^{3-}$ \\
\hline 0.8 & $\mathrm{MoO}_{3}{ }^{2} \mathrm{H}_{2} \mathrm{O}$ & 2 & $\mathrm{~V}_{10} \mathrm{O}_{28}{ }^{6-}$ \\
\hline & & $<2$ & $\mathrm{VO}_{2}{ }^{+}$ \\
\hline
\end{tabular}

In Tables 4 and 5,the adsorption of $\mathrm{Mo}(\mathrm{VI})$ and $\mathrm{V}(\mathrm{V})$ at various $\mathrm{pH}$ values for the $\mathrm{P}(\mathrm{ClVBTA})$ and IRA-402(Cl) resins at a concentration of $50 \mathrm{mg} \mathrm{L}^{-1}$ are presented. Both resins showed high retention percentages at $\mathrm{pH}$ 6-10, namely, above $83 \%$, for $\mathrm{Mo}(\mathrm{VI})$ at a concentration of $50 \mathrm{mg} \mathrm{L}^{-1}$.

Table 4. Retention of $50 \mathrm{mg} \mathrm{L}^{-1}$ of $\mathrm{Mo}(\mathrm{VI})$ at various $\mathrm{pH}$ values for the $\mathrm{P}(\mathrm{ClVBTA})$ and IRA-402(Cl) resins.

\begin{tabular}{|c|c|c|c|c|}
\hline & P(CIVBTA) & & IRA-402(CI) & \\
\hline $\mathbf{p H}$ & Retention (\%) & $\mathbf{~ m g ~ g ~}^{-1}$ resin & Retention (\%) & mg g $^{-1}$ resin \\
\hline 2 & 71.4 & 1.875 & 91.5 & 3.249 \\
\hline 4 & 77.1 & 2.272 & 94.7 & 3.772 \\
\hline 6 & 83.7 & 2.774 & 96.3 & 4.839 \\
\hline 8 & 65.5 & 2.059 & 97.4 & 4.688 \\
\hline 10 & 99.0 & 2.282 & 92.7 & 4.005 \\
\hline 12 & 0.00 & 0.000 & 94.3 & 4.172 \\
\hline
\end{tabular}

Table 5. Retention of $50 \mathrm{mg} \mathrm{L}^{-1}$ of $\mathrm{V}(\mathrm{V})$ at various $\mathrm{pH}$ values by the $\mathrm{P}(\mathrm{ClVBTA})$ and IRA-402(Cl) resins.

\begin{tabular}{|c|c|c|c|c|}
\hline & P(CIVBTA) & & IRA-402(CI) & \\
\hline $\mathbf{p H}$ & Retention (\%) & mg g $^{-1}$ resin & Retention (\%) & mg g $^{-1}$ resin \\
\hline 2 & 10.1 & 0.504 & 7.30 & 0.363 \\
\hline 4 & 73.8 & 3.411 & 76.4 & 3.292 \\
\hline 6 & 76.6 & 3.325 & 70.0 & 3.177 \\
\hline 8 & 80.7 & 3.744 & 84.5 & 4.084 \\
\hline 10 & 80.6 & 4.490 & 80.7 & 4.522 \\
\hline 12 & 8.00 & 0.467 & 81.1 & 4.571 \\
\hline
\end{tabular}

For the retention of $50 \mathrm{mg} \mathrm{L}^{-1}$ of $\mathrm{V}(\mathrm{V})$, the $\mathrm{P}(\mathrm{ClVBTA})$ and IRA-402(Cl) resins showed satisfactory performance, namely, they retained over $73 \%$ of the $\mathrm{V}(\mathrm{V})$ in the $\mathrm{pH}$ range of 4-10. $\mathrm{P}(\mathrm{ClVBTA})$ retained more $\mathrm{V}(\mathrm{V})$ than the commercial resin, namely, IRA-402(Cl), at the optimal $\mathrm{pH}$. For Mo(VI), the resins retained similar percentages.

To investigate additional properties of the $\mathrm{P}(\mathrm{ClVBTA})$ resin and to compare both ions with the commercial IRA-402(Cl) and with results from the literature ${ }^{28}$, $\mathrm{Mo}(\mathrm{VI})$ was removed as $\mathrm{MoO}_{4}{ }^{2-}$ at $\mathrm{pH} 6$ and $\mathrm{V}(\mathrm{V})$ was removed as $\mathrm{V}_{2} \mathrm{O}_{7}{ }^{4-}$ at $\mathrm{pH}$ 10.

\section{Thermodynamic parameter study}

Adsorption isotherms provide important information regarding the adsorption process and the interaction between the resin (adsorbent) with the metal ion (adsorbate). In Figures 6and 7,the adsorption profiles of the P(CIVBTA) and IRA-402 $(\mathrm{Cl})$ resins are presented with the $\mathrm{V}(\mathrm{V})$ metal ion at $\mathrm{pH} 10$ and $\mathrm{Mo}(\mathrm{VI})$ at $\mathrm{pH} 6$, respectively, at various temperatures.

Figure 6 demonstrates that the P(ClVBTA) and IRA-402 $(\mathrm{Cl})$ resins with V(V) at $\mathrm{pH} 10$ do not show a plateau; hence, they have not reached the maximum retention capacity. Figure 6.a) shows that the adsorption capacity of the $\mathrm{P}(\mathrm{ClVBTA})$ resin decreases as the temperature increases. At constant temperature $\left(25^{\circ} \mathrm{C}\right)$, a gradually increase of the $\mathrm{V}(\mathrm{V})$ concentration results in a higher retention at higher concentrations and $\mathrm{pH} 10$, whereas at lower concentrations, the retention does not change with an increase in the temperature. Figure 6.b) shows the opposite tendency for the IRA-402(Cl) commercial resin regarding the influence of the temperature on the retention of $\mathrm{V}(\mathrm{V})$ : an increase in the temperature is associated with an increase in the retention capacity. This is likely due to an increase in the kinetic energy of the metal ions and to a dilatation of the porous of IRA-402(Cl) resin with an increase in the temperature, which favors the diffusion of the metal ions through the active sites, thereby resulting in a higher adsorption at $35^{\circ} \mathrm{C}$.

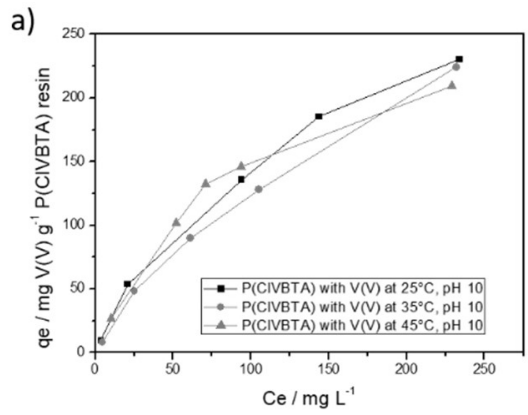

b)

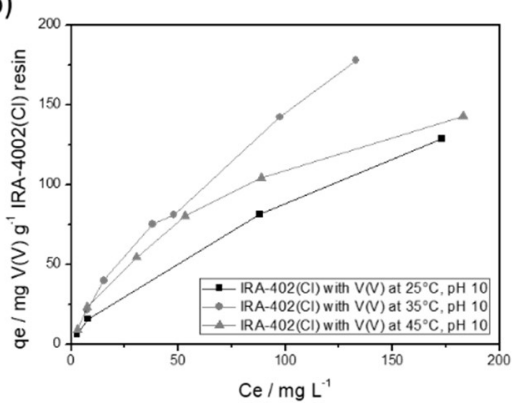

Figure 6. Isotherms profile of a) $\mathrm{P}(\mathrm{ClVBTA})$ and b) IRA-402(Cl) resins with $\mathrm{V}(\mathrm{V})$ at $\mathrm{pH} 10$ and 25,35 , and $45^{\circ} \mathrm{C}$. 
a)

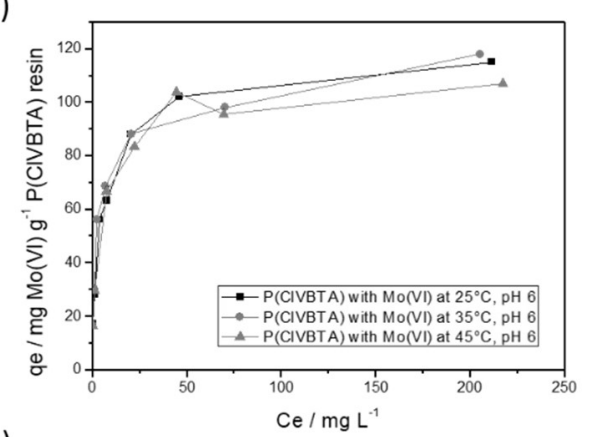

b)

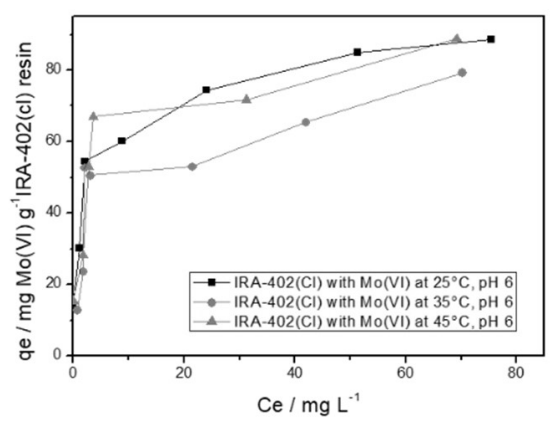

Figure 7. Isotherms profile of a) $\mathrm{P}(\mathrm{CIVBTA})$ and b) IRA-402(Cl) resins with $\mathrm{Mo}(\mathrm{VI})$ at $\mathrm{pH} 6$ and 25,35 , and $45^{\circ} \mathrm{C}$.

According to Figure 7, the $\mathrm{P}(\mathrm{ClVBTA})$ and IRA-402(Cl) resins reached a plateau that corresponds to the maximum retention capacity. According to Figure 7.a), theP(ClVBTA) resin with $\mathrm{Mo}(\mathrm{VI})$ presents a similar behavior to that of the resin that is charged with a $\mathrm{V}(\mathrm{V})$ metal ion solution. The $\mathrm{P}(\mathrm{ClVBTA})$ resin presents higher adsorption at $25^{\circ} \mathrm{C}$ up to a $\mathrm{Mo}(\mathrm{VI})$ ion solution concentration of $150 \mathrm{mg} \mathrm{L}^{-1}$; after that, it reaches the plateau, and with an increase in concentration, higher adsorption is exhibited at $35^{\circ} \mathrm{C}$. Figure 7.b) shows that the IRA-402 $(\mathrm{Cl})$ resin with $\mathrm{Mo}(\mathrm{VI})$ at $\mathrm{pH} 6$ presents the same trend as the $\mathrm{P}(\mathrm{ClVBTA})$ resin. The IRA-402 $(\mathrm{Cl})$ resin presents a higher adsorption at $25^{\circ} \mathrm{C}$ up to a concentration of $70 \mathrm{mg} \mathrm{L}^{-1}$; as the concentration is further increased, higher retention is realized at $45^{\circ} \mathrm{C}$.

According to the isotherm constants in Table 6,the P(CIVBTA) and IRA-402 (Cl) resins are more strongly correlated with the Langmuir isotherm for Mo(VI) and with the Freundlich model for V(V) ions. The Langmuir constant "b" is directly related to the affinity between the resin and the metal ion and the maximum retention capacity. These results suggest the formation of a monolayer. The $\mathrm{P}(\mathrm{ClVBTA})$ resin showed a larger constant of Langmuir in comparison with the IRA-402 $(\mathrm{Cl})$ resin, with high maximum capacities of retention $(117.6 \mathrm{mg}$ $\mathrm{Mog}^{-1}$ resin and $344.8 \mathrm{mg} \mathrm{V} \mathrm{g}^{-1}$ resin), which suggest a stronger resin/metal ion affinity under the experimental conditions of $\mathrm{pH} 6$ and 10 for $\mathrm{Mo}(\mathrm{VI})$ and $\mathrm{V}(\mathrm{V})$, respectively, at $25^{\circ} \mathrm{C}$.

At diference of vanadium (see fig. 6), it's retained a high concentration of molybdenum and very fast (during the first $120 \mathrm{sec}$, see fig. 8), we assumed that this is the reason of the irregular behavior at the starting of the plot.

Table 6. Constants of the isotherms of Langmuir and Freundlich for the $\mathrm{P}(\mathrm{ClBVTA})$ and IRA-402(Cl) resins with $\mathrm{V}(\mathrm{V})$ and $\mathrm{Mo}(\mathrm{VI})$ ions at $\mathrm{pH}$ values of 6 and 10 , respectively, at $25^{\circ} \mathrm{C}$.

\begin{tabular}{|c|c|c|c|c|c|c|c|}
\hline \multicolumn{5}{|c|}{ Langmuir } & \multicolumn{2}{c|}{ Freundlich } \\
\hline Resin & $\begin{array}{c}\text { Metal } \\
\text { ion }\end{array}$ & $\begin{array}{c}\text { qm(mg metalg- } \\
\text { resin) }\end{array}$ & $\mathrm{b}_{\left(\mathrm{L} \mathrm{mg}^{-1}\right)}$ & $\mathrm{R}^{2}$ & $\mathrm{~N}$ & $\begin{array}{c}\mathrm{K}_{\mathrm{f}} \\
\left(\mathrm{mg} \mathrm{Mo} \mathrm{g}^{-1} \text { resin }\right)\end{array}$ & $\mathrm{R}^{2}$ \\
\hline $\mathrm{P}(\mathrm{ClVBTA})$ & $\mathrm{Mo}(\mathrm{VI})$ & 117.6 & 0.224 & 0.999 & 3.093 & 27.55 & 0.840 \\
\hline & $\mathrm{V}(\mathrm{V})$ & 344.8 & 0.008 & 0.982 & 1.318 & 4.21 & 0.984 \\
\hline IRA-402(Cl) & $\mathrm{Mo}(\mathrm{VI})$ & 90.1 & 0.414 & 0.996 & 3.156 & 25.95 & 0.744 \\
\hline & $\mathrm{V}(\mathrm{V})$ & 185.2 & 0.011 & 0.960 & 1.388 & 3.23 & 0.997 \\
\hline
\end{tabular}

Table 7 presents the Langmuir constants of the $\mathrm{P}(\mathrm{ClVBTA})$ resin at various temperatures. From these data, it is possible calculate the thermodynamic parameters, such as the Gibbs free energy $\Delta \mathrm{G}^{\circ}$, the enthalpy $\Delta \mathrm{H}^{\circ}$, and the entropy $\Delta \mathrm{S}^{\circ}$.

Table 7. Constants of Langmuir at various temperatures for the P(CIVBTA) resin that is charged with $\mathrm{Mo}(\mathrm{VI})$ and $\mathrm{V}(\mathrm{V})$ at $\mathrm{pH}$ values of 6 and 10 , respectively.

\begin{tabular}{|c|c|c|c|c|}
\hline \multicolumn{5}{|c|}{ Langmuir constants } \\
\hline $\begin{array}{c}\text { Temperature } \\
\left({ }^{\circ} \mathrm{C}\right)\end{array}$ & Metal ion & $\begin{array}{c}\mathrm{q}_{\mathrm{m}} \\
(\mathrm{mg} \text { metal g-1 }) \\
\mathrm{P}(\mathrm{ClVBTA})\end{array}$ & $\begin{array}{c}\mathrm{b} \\
\left(\mathrm{L} \mathrm{mg}^{-1}\right)\end{array}$ & $\mathrm{R}^{2}$ \\
\hline 25 & $\mathrm{Mo}(\mathrm{VI})$ & 117.6 & 0.224 & 0.999 \\
\hline & $\mathrm{V}(\mathrm{V})$ & 344.8 & 0.008 & 0.982 \\
\hline 35 & $\mathrm{Mo}(\mathrm{VI})$ & 119.0 & 0.209 & 0.996 \\
\hline & $\mathrm{V}(\mathrm{V})$ & 454.5 & 0.004 & 0.950 \\
\hline 45 & $\mathrm{Mo}(\mathrm{VI})$ & 108.7 & 0.261 & 0.998 \\
\hline & $\mathrm{V}(\mathrm{V})$ & 303.0 & 0.010 & 0.996 \\
\hline
\end{tabular}

The free energy $\Delta \mathrm{G}^{\circ}$ is calculated by equation (9) using the constant of Langmuir.

$$
\Delta G^{\circ}=-R T \ln b
$$

The enthalpy and entropy, namely, $\Delta \mathrm{H}^{\circ}$ and $\Delta \mathrm{S}^{\circ}$, can be obtained by the relation of Vant Hoff, which is presented as equation (10).

$$
\log (b)=\frac{\Delta S^{\circ}}{2.303 R}-\frac{\Delta H^{\circ}}{2.303 R T}(10)
$$

It is possible to determine $\Delta \mathrm{H}^{\circ}$ and $\Delta \mathrm{S}^{\circ}$ from the slope and the intercept, respectively, in the plot of $\log (\mathrm{b})$ vs $1 / \mathrm{T}$.

Table 8. Thermodynamic parameters for the $\mathrm{P}(\mathrm{ClVBTA})$ resin with $\mathrm{Mo}(\mathrm{VI})$ and $\mathrm{V}(\mathrm{V})$ at $\mathrm{pH}$ values of 6 and 10 , respectively.

\begin{tabular}{|c|c|c|c|c|}
\hline $\mathbf{T} / \mathbf{K}$ & Metal ion & $\Delta \mathbf{G}^{\circ} / \mathbf{k J} \mathbf{~ m o l}^{\mathbf{1}}$ & $\Delta \mathbf{H}^{\circ} / \mathbf{k J} \mathbf{~ m o l}^{-1}$ & $\Delta \mathbf{S}^{\circ} / \mathbf{k J ~ m o l}^{\mathbf{1}}$ \\
\hline 298.15 & $\mathrm{Mo}(\mathrm{VI})$ & 3.706 & & \\
\hline & $\mathrm{V}(\mathrm{V})$ & 11.993 & & \\
\hline 308.15 & $\mathrm{Mo}(\mathrm{VI})$ & 4.006 & $5.808(\mathrm{Mo})$ & $0.07(\mathrm{Mo})$ \\
\hline & $\mathrm{V}(\mathrm{V})$ & 14.065 & $8.459(\mathrm{~V})$ & $-0.014(\mathrm{~V})$ \\
\hline 318.15 & $\mathrm{Mo}(\mathrm{VI})$ & 3.557 & & \\
\hline & $\mathrm{V}(\mathrm{V})$ & 12.186 & & \\
\hline
\end{tabular}

Table 8 summarizes the $\Delta \mathrm{G}^{\circ}, \Delta \mathrm{H}^{\circ}$, and $\Delta \mathrm{S}^{\circ}$ values obtained for the adsorptions of $\mathrm{Mo}(\mathrm{VI})$ and $\mathrm{V}(\mathrm{V})$ by the $\mathrm{P}(\mathrm{ClVBTA})$ resin. The free energy values substantially depend on the temperature. The values are positive; hence, the adsorptions of $\mathrm{Mo}(\mathrm{VI})$ and $\mathrm{V}(\mathrm{V})$ are non-spontaneous processes. This finding is supported by the small constants of Langmuir that were obtained previously. The enthalpy suggests endothermic processes of $\mathrm{Mo}(\mathrm{VI})$ and $\mathrm{V}(\mathrm{V})$ adsorption, namely, we must input energy into the system. The value of entropy for Mo(VI) suggests an increase in the randomness (increase in the number of species) in the $\mathrm{P}(\mathrm{ClVBTA})$ resin surface. The entropy value forV $(\mathrm{V})$ suggests a decrease in the number of degrees of freedom, which is due to the metal ion being retained by the $\mathrm{P}(\mathrm{CIVBTA})$ resin and transformed to a more organized state.

Finally, according to the enthalpy values, the adsorptions of $\mathrm{Mo}(\mathrm{VI})$ at $\mathrm{pH} 6$ and $\mathrm{V}(\mathrm{V})$ at $\mathrm{pH} 10$ in the $\mathrm{P}(\mathrm{ClVBTA})$ resin are essentially physical processes.

\section{Kinetic study}

Figure 8presents the kinetic profiles of the $\mathrm{P}(\mathrm{ClVBTA})$ and IRA-402(cl) resins that are charged with $\mathrm{V}(\mathrm{V})$ and $\mathrm{Mo}(\mathrm{VI})$. For the $\mathrm{P}(\mathrm{ClVBTA})$ resin, Figure 8.a) shows that equilibrium is reached during the first $120 \mathrm{sec}$ for both metal ions and that more $\mathrm{V}(\mathrm{V})$ than $\mathrm{Mo}(\mathrm{VI})$ can be retained. Meanwhile, according to Figure 8.b), the commercial IRA-402(Cl) resin at $1200 \mathrm{sec}$ does not reach equilibrium and can retain more $\mathrm{Mo}(\mathrm{VI})$ than $\mathrm{V}(\mathrm{V})$. 

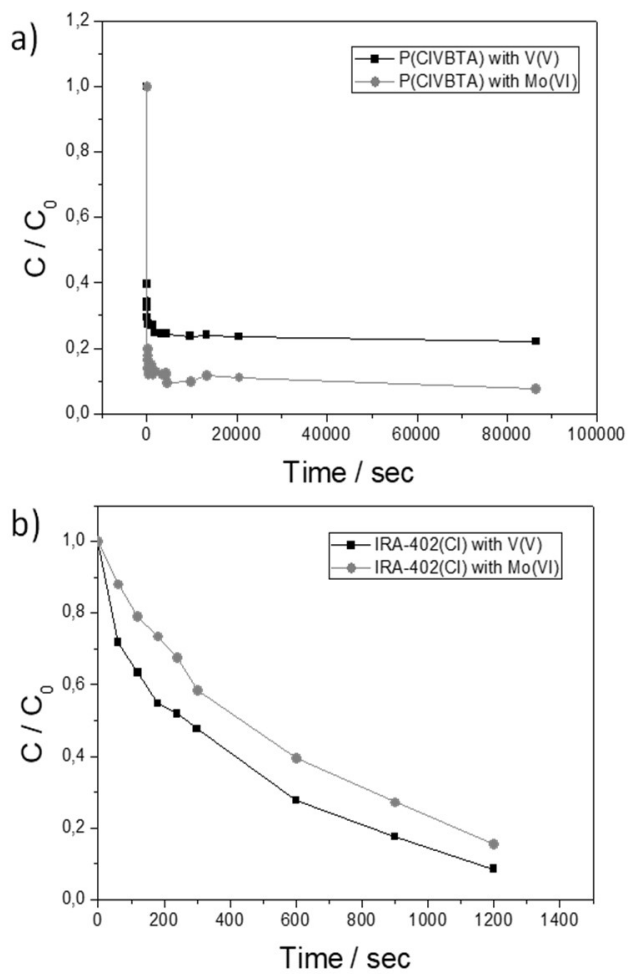

Figure 8. Kinetic profiles of a) the $\mathrm{P}(\mathrm{ClVBTA})$ resin and b) the IRA-402(Cl) resin with $\mathrm{V}(\mathrm{V})$ represented by squares and $\mathrm{Mo}(\mathrm{VI})$ by circles.

Table 9 presents the values of the kinetic data that have been adjusted to the pseudo-first-order and pseudo-second-order kinetic models by equations (5) and (8) for the P(ClVBTA) and IRA-402(Cl) resins with $\mathrm{Mo}(\mathrm{VI})$ and $\mathrm{V}(\mathrm{V})$ metal ions. The $\mathrm{P}(\mathrm{ClVBTA})$ resin with $\mathrm{Mo}(\mathrm{VI})$ follows a pseudo-first-order kinetic mechanism, whereas with $\mathrm{V}(\mathrm{V})$,it follows a pseudo-second-order mechanism. The IRA-402(Cl) resin with $\mathrm{Mo}(\mathrm{VI})$ and $\mathrm{V}(\mathrm{V})$ metal ions follows a pseudo-firstorder kinetic mechanism.

Table 9. Evaluation of the kinetic data for the $\mathrm{P}(\mathrm{ClVBTA})$ and IRA-402(Cl) resins using conventional pseudo-first-order and pseudo-second-order equations.

\begin{tabular}{|c|c|c|c|}
\hline \multicolumn{2}{|c|}{ Resin } & P(CIVBTA) & IRA-402(CI) \\
\hline Model & Metal ion & $\mathrm{R}^{2}$ & $\mathrm{R}^{2}$ \\
\hline Firstorder & $\mathrm{Mo}(\mathrm{VI})$ & 0.983 & 0.997 \\
\hline & $\mathrm{V}(\mathrm{V})$ & 0.600 & 0.988 \\
\hline Secondorder & $\mathrm{Mo}(\mathrm{VI})$ & 0.600 & 0.986 \\
\hline & $\mathrm{V}(\mathrm{V})$ & 0.995 & 0.953 \\
\hline
\end{tabular}

\section{CONCLUSIONS}

$\mathrm{P}(\mathrm{ClVBTA})$ resin containing ammonium quaternary groups was successfully synthesized, and this resin retained more $\mathrm{Mo}(\mathrm{VI})$ and $\mathrm{V}(\mathrm{V})$ metal ions than the commercial IRA-402(Cl) resin at $\mathrm{pH}$ values of 6 and 10, respectively. This finding can be attributed to the resin's high water adsorption capacity, which is supported by the small particle size and non-uniform shape, as observed by SEM.

The $\mathrm{P}(\mathrm{ClVBTA})$ and IRA-402(Cl) resins were more strongly correlated with the Langmuir isotherm for $\mathrm{Mo}(\mathrm{VI})$ and with the Freundlich model for $\mathrm{V}(\mathrm{V})$ ions. This suggests the formation of a monolayer. The $\mathrm{P}(\mathrm{ClVBTA})$ resin shows higher maximum retention capacity (117.6 $\mathrm{mg} \mathrm{Mo} \mathrm{g}^{-1}$ resin and $344.8 \mathrm{mg} \mathrm{V} \mathrm{g}^{-1}$ resin), which suggests a higher-affinity resin/metal ion than the IRA-402(Cl) resin under the experimental conditions of $\mathrm{pH} 6$ and 10 for $\mathrm{Mo}(\mathrm{VI})$ and $\mathrm{V}(\mathrm{V})$, respectively, at $25^{\circ} \mathrm{C}$. The values of the free energy, enthalpy, and entropy for the $\mathrm{P}(\mathrm{ClVBTA})$ resin suggest that the adsorptions of $\mathrm{Mo}(\mathrm{VI})$ and $\mathrm{V}(\mathrm{V})$ are non spontaneous endothermic processes that result an increases in the randomness (increases in the number of species of $\mathrm{Mo}$ ) on the $\mathrm{P}(\mathrm{ClVBTA})$ resin surface.
These values for $\mathrm{V}(\mathrm{V})$ suggest a decrease in the number of degrees of freedom because the metal ion is retained by the $\mathrm{P}(\mathrm{ClVBTA})$ resin and transitions to a more organized state. The adsorption of $\mathrm{Mo}(\mathrm{VI})$ and $\mathrm{V}(\mathrm{V})$ at $\mathrm{pH}$ values of 6 and 10 , respectively, are essentially physical processes.

Finally, the P(ClVBTA) resin showed faster kinetics than the commercial IRA$402(\mathrm{Cl})$ resin and reached the maximum retention capacity during the first 120 sec for $\mathrm{Mo}(\mathrm{VI})$ and $\mathrm{V}(\mathrm{V})$ metal ions at $\mathrm{pH}$ values of 6 and 10, respectively.

\section{ACKNOWLEDGEMENTS}

The authors thank to FONDECYT (Grant No. 1190469). DVM thanks to ANID/FONDECYT Postdoctorado (Grant No. 3200467).

\section{REFERENCES}

1. Barkhordar B, G. M. Comparision of Langmuir and Freundlich Equilibriums in $\mathrm{Cr}, \mathrm{Cu}$ and $\mathrm{Ni}$ Adsorption by Sargassum IranNo Title. J. Env. Heal. Sci. Eng.2004, 1, 58-64.

2. Borbely, G., Nagy, E. Removal of Zinc and Nickel Ions by Complexation Membrane Filtration Process from Industrial Wastewater. Desalination 2009, $240(1-3), 218-226$

3. Korus, I. Loska, K. Removal of $\mathrm{Cr}(\mathrm{III})$ and $\mathrm{Cr}(\mathrm{VI})$ Ions from Aqueous Solutions by Means of Polyelectrolyte-Enhanced Ultrafiltration. Desalination 2009, 247, 390-395.

4. Pedersen, A. J. Characterization and Electrolytic Treatment of Wood Combustion Fly Ash for the Removal of Cadmium. Biomass Bioenergy 2003, 25 (4), 447-458.

5. Rivas, B. L.; Espinosa, C.; Sánchez, J. Application of the Liquid-Phase Polymer-Based Retention Technique to the Sorption of Molybdenum(VI) and Vanadium (V). Polym. Bull.2019, 76, 539-552.

6. Morales, D. V.; Kusku, O.; Rivas, B. L.; Muserref, A.; Kabay, N.; Bryjak, M. Removal of Cr(VI) by Stabilized Solvent Impregnated Resin(SIR) Prepared by Using a Hydrophilic Polymer Adsorbent and Aliquat 336. J. Chil. Chem. Soc.2019, 64, 4432-4436.

7. Núñez, D.; Serrano, J. A.; Mancisidor, A.; Elgueta, Elizabeth Kokkarachedu, V.; Oyarzún, P.; Cáceres, R.; Ide, W.; Rivas., B. L. Heavy Metal Removal from Aqueous Systems Using Hydroxyapatite Nanocrystals Derived from Clam Shells. RSC Adv.2019, 9, 22883-22890.

8. Sánchez, J.; Rivas., B. L. Liquid-Phase Polymer-Based Retention to Remove Arsenic from Water: A Mini Review. J. Chil. Chem. Soc.2019, 64, 44324522.

9. Tapiero, Y.; Sánchez, J.; Rivas, B. L. Activated Polypropylene Membranes with Ion-Exchange Polymers to Transport Chromium Ions in Water. J. Chil. Chem. Soc.2019, 64, 4597-4606.

10. Mitchell, P.C.H. Ullman's Encyclopedia of Industrial Chemistry, 5th Ed.; VCH, Ed.; 1986.

11. Rivas BL, Pooley SA, Pereira ED, Cid R, Luna M, Jara, MA, Geckeler, KE Water-soluble amine and imine polymers with the ability to bind metal ions in conjunction with membrane filtration, J. Appl. Polym. Sci. 2005, 96, 222231.

12. Sastre, A.M.; Alguacil, F. J. Co-Extraction and Selective Stripping of Copper(II) and Molybdenum(VI) Using LIX 622. Chem. Eng. J.2001, 81, $109-112$

13. Liansheng, X.; Qixiu, Z.; Bofan, G.; Shaoying, H. Separation of Molybdenum from Tungstate Solution by a Combination of Moving Packed Bed and Fluid Ion-Exchange Techniques. Int. J. Refract. Met. Hard Mater.2001, 19, 145 - 148.

14. Juneja, J.M.; Singh, S.; Bose, D. K. Investigations on the Extraction of Molybdenum and Rhenium Values from Low Grade Molybdenite Concentrate. Hydrometallurgy1996, 41, 201-209.

15. Guibal, E.; Milot, C.; Roussy, J. Influence of Hydrolysis Mechanisms on Molybdate Sorption Isotherms Using Chitosan. Sep. Sci. Technol.2000, 35, 1021-1038.

16. Hua, T.; Haynesa, R. J.; Zhou, Y.-F.; Boullemant, A.; Chandrawana, I Potential for Use of Industrial Waste Materials as Filter Media for Removal of Al, Mo, As, V and Ga from Alkaline Drainage in Constructed Wet Lands - Adsorption Studies. Water Res.2015, 71, 32-41.

17. Rivas B. L, Maturana H.A, Pereira, ED. Metal ion binding properties of synthetic vinyl resins. Angew. Makromol. Chem. 1994, 220, 61-74.

18. Mitchell, P. C. H. Ullmann's Encyclopedia of Industrial Chemistry; 1990; pp 675-682.

19. Aveston, J., Anacker, E.W. Johnson, J. S. Hydrolysis of Molybdenum (VI). Ultracentrifugation, Acidity Measurements, and Raman Spectra of Polymolybdates. Inorg. Chem.1964, 3 (5), 735-746. 
20. Busey, R.H., and Keller, O. L. Structure of the Aqueous Pertechnetate Ion by Raman and Infrared Spectroscopy. Raman and Infrared Spectra of Crystalline $\mathrm{KTcO}_{4}, \mathrm{KReO}_{4}, \mathrm{Na}_{2} \mathrm{MoO}_{4}, \mathrm{Na}_{2} \mathrm{WO}_{4}, \mathrm{Na}_{2} \mathrm{MoO}_{4} \cdot 2 \mathrm{H}_{2} \mathrm{O}$, and $\mathrm{Na}_{2} \mathrm{WO}_{4} \cdot 2 \mathrm{H}_{2} \mathrm{O} . J$. Chem. Phys.1964, 41 (1), 215-225.

21. Bartecki, A. and Dembicka, D. Spectroscopy of Molybdenum(VI) Compounds. J. Inorg. Nucl. Chem. 1967, 29 (12), 2907-2916.

22. Roschin AV Toxicology of vanadium compounds used in modern industry. Water Research 1967, 32, 26-32

23. Cotton, F.A. and Wilkinson, G. Advanced Inorganic Chemistry, 5th editio.; Sons, J. W. \&, Ed.; 1988.

24. Kusku, O.; Rivas, B. L.; Urbano, B. F.; Arda, M.; Kabay, N.; Bryjak, M. A Comparative Study of Removal of Cr(VI) by Ion Exchange Resins Bearing Quaternary Ammonium Groups. J. Chem. Technol. Biotechnol.2014, 89 (6), 851-857.
25. Pérez, J.; Toledo, L.; Campos, C. H.; Yañez, J.; Rivas, B. L.; Urbano, B. F. Arsenic Sorption onto an Aluminum Oxyhydroxide-Poly[(4Vinylbenzyl)Trimethylammonium Chloride] Hybrid Sorbent. RSC Adv. 2016, 6 (34), 28379-28387.

26. Moraga, B.; Toledo, L.; Jelínek, L.; Yañez, J.; Rivas, B. L.; Urbano, B. F. Copolymer-Hydrous Zirconium Oxide Hybrid Microspheres for Arsenic Sorption. Water Res. 2019, 116, 115044-115054.

27. Demircioğlu, M,; Kocacık, N.; Yiğit, E. and K. N. Removal of Metal Pollutants (Cd, U) from Phosphoric Acid Solutions by Ion Exchange II. Mathematical Modeling. Innov. Miner. Coal Process. 1998, 781-785.

28. Morales, D. V.; Rivas, B. L.; González, M. Synthesis and Characterization of Poly([(2-Methacryloyloxy) Ethyl]) Trimethylamonnium Chloride) Resin with Removal Properties for Vanadium(V) and Molybdenum(VI). J. Chil. Chem. Soc. 2016, 61 (4), 3295-3303. 